\title{
Identifying the Range of Micro-Events Preceding the Critical Point in the Destruction Process in Traditional and Quasi-Brittle Cement Composites with the Use of a Sound Spectrum
}

\author{
Dominik Logoń ${ }^{1, * \mathbb{C}}$, Janusz Juraszek ${ }^{2} \mathbb{D}$, Zbynek Keršner ${ }^{3} \mathbb{D}$ and Petr Frantík ${ }^{3}$ \\ 1 Faculty of Civil Engineering, Wrocław University of Science and Technology, Wybrzeże Wyspiańskiego 27, \\ 50-370 Wrocław, Poland \\ 2 Faculty of Materials, Civil and Environmental Engineering, University of Technology and Humanities in \\ Bielsko-Biała, Willowa 2, Building C, 43-309 Bielsko-Biała, Poland; jjuraszek@ath.bielsko.pl \\ 3 Faculty of Civil Engineering, Brno University of Technology, Veveři 331/95, 60200 Brno, Czech Republic; \\ kersner.z@fce.vutbr.cz (Z.K.); frantik.p@fce.vutbr.cz (P.F.) \\ * Correspondence: dominik.logon@pwr.edu.pl
}

check for updates

Citation: Logoń, D.; Juraszek, J.; Keršner, Z.; Frantík, P. Identifying the Range of Micro-Events Preceding the Critical Point in the Destruction Process in Traditional and Quasi-Brittle Cement Composites with the Use of a Sound Spectrum. Materials 2021, 14, 1809. https:// doi.org/10.3390/ma14071809

Academic Editor: Leif Kari

Received: 31 January 2021

Accepted: 29 March 2021

Published: 6 April 2021

Publisher's Note: MDPI stays neutral with regard to jurisdictional claims in published maps and institutional affiliations.

Copyright: (c) 2021 by the authors. Licensee MDPI, Basel, Switzerland. This article is an open access article distributed under the terms and conditions of the Creative Commons Attribution (CC BY) license (https:// creativecommons.org/licenses/by/ $4.0 /)$.

\begin{abstract}
This paper presents the possibilities of determining the range of stresses preceding the critical destruction process in cement composites with the use of micro-events identified by means of a sound spectrum. The presented test results refer to the earlier papers in which micro-events (destruction processes) were identified but without determining the stress level of their occurrence. This paper indicates a correlation of $2 / 3$ of the stress level corresponding to the elastic range with the occurrence of micro-events in traditional and quasi-brittle composites. Tests were carried out on beams (with and without reinforcement) subjected to four-point bending. In summary, it is suggested that the conclusions can be extended to other test cases (e.g., compression strength), which should be confirmed by the appropriate tests. The paper also indicates a need for further research to identify micro-events. The correct recognition of micro-events is important for the safety and durability of traditional and quasi-brittle cement composites.
\end{abstract}

Keywords: AE acoustic emission; micro-events; sound spectrum; traditional and quasi-brittle cement composites

\section{Introduction}

Acoustic Emission (AE) is a well-researched method for testing building materials and structures, which has been used for a very long time in civil engineering [1-6]. As a review of the literature shows, papers concentrate on determining the destruction process of materials. AE has been used in monitoring early-age and early hydration acoustic emission of cement paste $[7,8]$. This method was used to determine the Hooke's law range and identify the destruction process in cement composites in various cases of loading [9-12]. AE (events sum AE) has been applied to determine the first crack [13-15], micro- and macro-cracks and their propagation in the fracture process in traditional and quasi-brittle cement composites with and without reinforcement [16-23]. Previous tests show the possibility of using AE in various materials, including traditional and high-strength [24-27] cement composites. The effectiveness of the acoustic emission measurements has been used to monitor structures [28-30]. Diagnostics and structure monitoring are still being modified with this method [31-33].The majority of papers concerning the destruction process identification are based on the measurement of the AE and AE sum as well as on the spectrograms of the AE signals. Research papers have also demonstrated the possibility of recording the destruction stages with the use of spectrogram images [4].

Various methods of stress determination are still being improved in the process of identification of failure processes in different materials and structures [34-39], but the correlation of the stress level with AE in terms of Hooke's law has not been applied. 
Previous research work focused on the correlation between AE and the failure processes of each of the composite components based on the sound spectrum [40-45]. It has been found that, for the accurate recognition of composite failure processes, the $\mathrm{AE}$ recording should be expanded to include the analysis of each sound separately (as well as a single signal in a very small range of frequencies) and the analysis of the range of sounds corresponding to a given mechanical effect with the use of an acoustic spectrum. It was noticed that the 2D and 3D acoustic spectra should be correlated with the load-deflection curve and with other acoustic effects, which enables the identification of the failure process.

Previous papers $[46,47]$ have focused on the possibility of identifying AE micro-events in the area preceding the occurrence of a critical crack initiating the destruction process in cement composites. It has been indicated that there is a possibility of predicting the occurrence of the $\mathrm{f}_{\mathrm{cr}}$ (first crack) based on an analysis of the 2D and 3D sound spectra corresponding to the occurring groups of micro-events that precede the end of the loaddeflection approximate proportionality area. Tests were conducted on a small-size $(40 \mathrm{~mm}$ $\times 40 \mathrm{~mm} \times 160 \mathrm{~mm}$ ) specimen of a paste with dispersed reinforcement.

This paper indicates the occurrence of micro-events in a wide range of large cement composite beams (paste, mortar and concrete) with traditional and dispersed reinforcement. Before a decision was made on including examples of specimens in this paper, a wide range of composites were analysed and extremely different specimens were selected. The identification of micro-events was carried out by recording the $\mathrm{AE}$ on beams with a dimension of $150 \mathrm{~mm} \times 150 \mathrm{~mm} \times 600 \mathrm{~mm}$. Conclusions were drawn based on the analysis of the sound spectrum and the corresponding amplitudes. The repeatability of the results indicates the possibility of considering the conclusions presented in this paper as more generally applicable. The main goal of this paper is the assessment of the level of stress at which micro-events appear that precede the occurrence of the critical crack $f_{c r}$ (LOP - the limit of proportionality) and the flexural strength at bending $\mathrm{f}_{\max }$ (MOR-the modulus of rupture).

The originality of the presented paper relates to the determination of the stress level (2/3 of the elastic range) for which there occurs the grouping of micro-events in the frequency range and the increase in relative amplitudes of the sound spectrum that precede the destruction process of cement composites. The paper does not identify the types and causes of the micro-events, indicating the need for such research in the future.

\section{Materials and Methods}

The AE tests were carried out on the specimens that were presented in previous papers. The specimens were selected in a manner ensuring that they differ significantly in terms of reinforcement and deformation capacity [43-49]. Acoustic measurements concentrated on the recording of micro-events. The micro-events were recognized by the space sound spectrum in the range of $0.2-20 \mathrm{kHz}$.

\subsection{Materials Used for Tests}

Materials for the preparation of the cement composites: c-Portland cement CEM I (class 42.5R) produced by "Górażdże" cement plant in Górażdże (Poland), silica fume (10\% of cement mass), fly ash ( $20 \%$ of cement mass), sand of $0-2 \mathrm{~mm}$, superplasticizer (SP) and tap water $(w)$, with the $w / b=0.35(b=$ cement + fly ash + silica fume).

\section{Composites:}

(1) Mortar without reinforcement-cement:sand (volume) = 1:4.5.

(2) The paste composite was reinforced with dispersed synthetic structural polypropylene fibres (compliance with ASTM C-1116)—specific weight $0.91 \mathrm{~kg} / \mathrm{dm}^{3}$, flexural strength $\mathrm{f}_{\mathrm{t}}=620-758 \mathrm{MPa}, \mathrm{E}=4.9 \mathrm{GPa}, 1=54 \mathrm{~mm}$, equivalent diameter $0.48 \mathrm{~mm}$, $1 / \mathrm{d}=113$ and $\mathrm{V}_{\mathrm{f}}=6 \%$.

(3) The concrete composite was reinforced with traditional continuous ST500-b reinforcing bars (ArcelorMittal, Warsaw, Poland) with a diameter $(\mathrm{d})=10 \mathrm{~mm}$. Four 
continuous structural bars in the corners of the beam were placed with stirrups of $\mathrm{d}=6 \mathrm{~mm}$, positioned every $150 \mathrm{~mm}$.

\subsection{Preparation of Specimens for Tests}

The ingredients were mixed in the concrete mixer and then used to cast the samples. Beams $(150 \mathrm{~mm} \times 150 \mathrm{~mm} \times 600 \mathrm{~mm})$ were cast in slabs and then cured in water at $20 \pm 2{ }^{\circ} \mathrm{C}$. After 180 days of ageing, the beams were prepared for the bending tests.

The concrete specimens with traditional reinforcement were not notched. The paste and mortar samples were notched. These beams were turned $90^{\circ}$ and cut to the depth of $30 \mathrm{~mm}$. The width of the cut was $3 \mathrm{~mm}$.

\subsection{Description of the Test Stand}

Four-point bending tests were carried out in the testing machine with closed-loop servo control displacement, see Figure 1. The load-deflection curves were obtained according to ASTM C 1018 but the tests were based on the measurement of the continuous and constant displacement of crosshead and the rate was $1 \mathrm{~mm} / \mathrm{min}$. The following data were obtained:

- the flexural strength at bending $\mathrm{f}_{\max }$ (MOR-the modulus of rupture), and the flexural strength at the first crack $\mathrm{f}_{\mathrm{cr}}$ (LOP-the limit of proportionality);

- $\quad$ the characteristic points on the load-deflection curve, $\mathrm{f}_{\mathrm{x}}\left(\mathrm{F}_{\mathrm{x}}\right.$-load; $\varepsilon_{\mathrm{x}}$-deflection; $\mathrm{W}_{\mathrm{x}^{-}}$ energy);

- energy (work) as proportional to the area under the load-deflection curve up to the characteristic point.

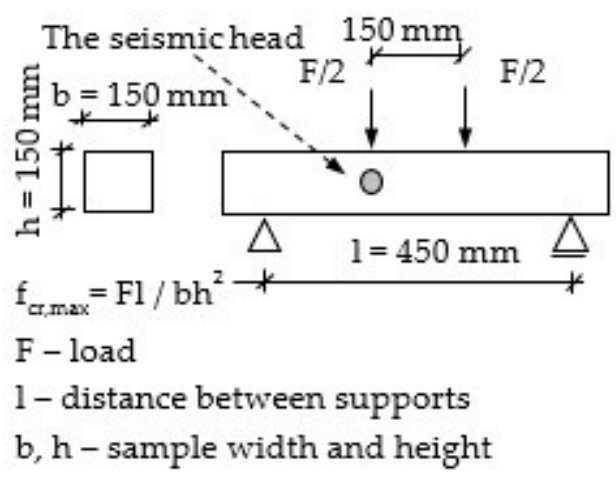

(a)

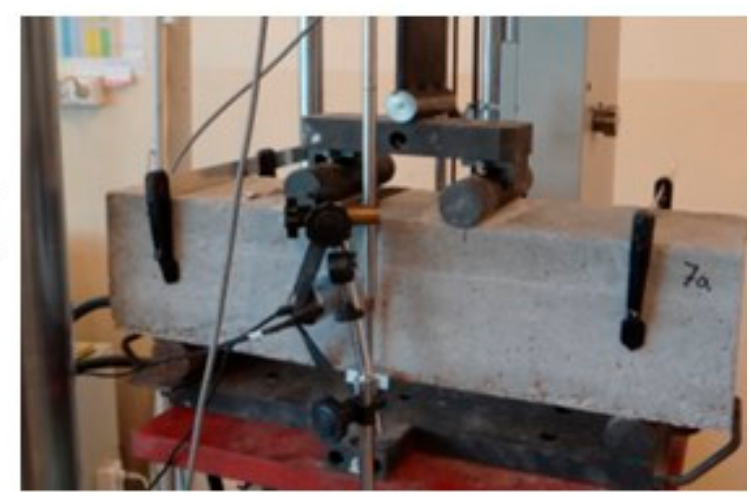

(b)

Figure 1. Four-point bending test: the specimen before the test in the test machine: (a) diagram of the test [44], (b) the specimen before test.

Acoustic emission effects (AE) were registered and recorded in order to monitor the progress of the cracking process during the monitoring of the load-deflection curve. A seismic head HY919 was used to record the acoustic emission effects in the range from 0.2 to $20 \mathrm{kHz}$. The sampling rate of the recorded waveforms was $44.1 \mathrm{kHz}$. The head was placed on the side in the central part of the loaded beams.

The mechanical effects of the composites were correlated with the recorded acoustic spectrum effects. The 3D and 2D sound spectra were measured with the use of the Spectra PLUS-SC program (Pioneer Hill Software LLC, Sequim, WA, USA). The measured AE effects were presented as 3D and 2D acoustic spectra.

The load-deflection curves of quasi-brittle cement composites with the corresponding acoustic effects (including sound spectra) are presented. Based on the results included in this paper (and [44]), Figure 2 has been modified by adding micro-events. The spectrum of micro-events was placed directly above the background noise spectrum and below the 
spectrum corresponding to the micro-crack. The 2D spectra (Figure 2c-amplitude and corresponding frequencies) were determined in relation to an established test duration point correlated with the destruction process, see Figure 2a. The determination of 2D spectra in the time range of the occurrence of the same destruction phenomena increases the range of amplitudes and should not be compared with the spectrum referred to the established test duration point. Infrasound, low- and very high-frequency sounds were not measured; this frequency range is also intended to be recorded in future tests, but it requires heads with a different measurement range.

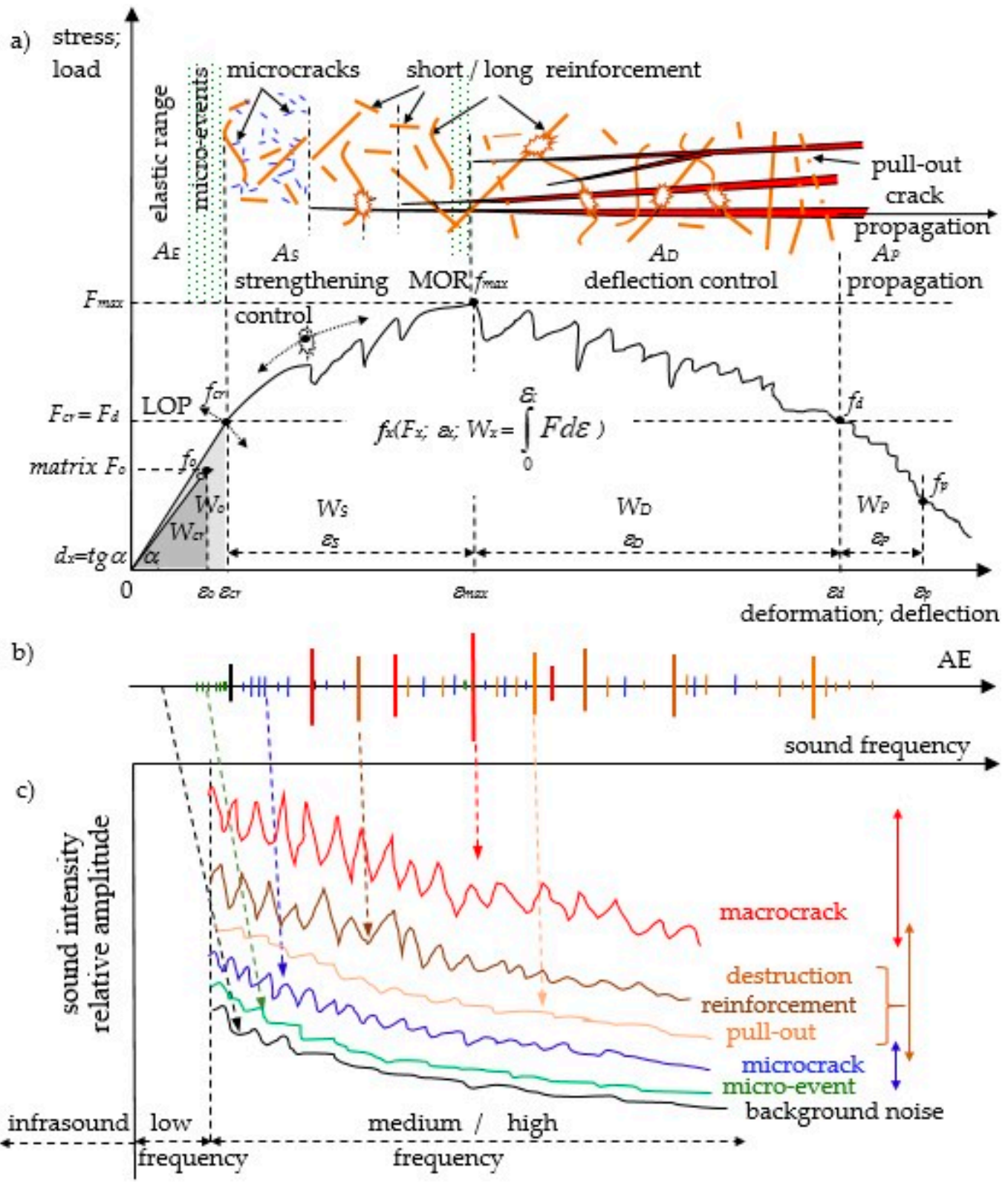

Figure 2. The quasi-brittle composite: (a) load-deflection curve; (b) AE-acoustic emission effects; (c) 2D acoustic spectrum (amplitude depending on sound intensity and frequency).

The ESD reinforcement effect (Eng. elastic range, strengthening control and deflection control) is presented by characteristic points $\mathrm{f}_{\mathrm{x}}$ (load $\mathrm{F}_{\mathrm{x}}$; deflection $\varepsilon_{\mathrm{x}}$; absorbed energy $\mathrm{W}_{\mathrm{x}}$ ). The absorbed energy is determined as the area under the load-deflection curve. The following symbols are used: $A_{E}, W_{E}$ (the area and absorbed energy corresponding to the elastic range); $\mathrm{A}_{\mathrm{S}}, \mathrm{W}_{\mathrm{S}}$ (the area and absorbed energy corresponding to the strengthening 
control); $A_{D}, W_{D}$ (the area and absorbed energy corresponding to the deflection control); and $A_{P}, W_{P}$ (the area and absorbed energy corresponding to the propagation). Deformation ability was determined as $d_{x}=$ load/deflection.

\section{Results}

Figure 3 presents the examples of the tested specimens in the bending test. A specimen of mortar without reinforcement demonstrates the characteristic catastrophic brittle destruction process after achieving $\mathrm{f}_{\mathrm{cr}}=\mathrm{f}_{\max }$. At the critical point $\mathrm{f}_{\mathrm{x}}$ (load; deflection; energy), the following results were obtained: $\mathrm{f}_{\mathrm{cr}}=\mathrm{f}_{\max }(13.0 \mathrm{kN} ; 0.71 \mathrm{~mm} ; 4.658 \mathrm{~J})$. The deformation ability is $\operatorname{tg} \alpha=18.2 \mathrm{kN} / \mathrm{mm}$.

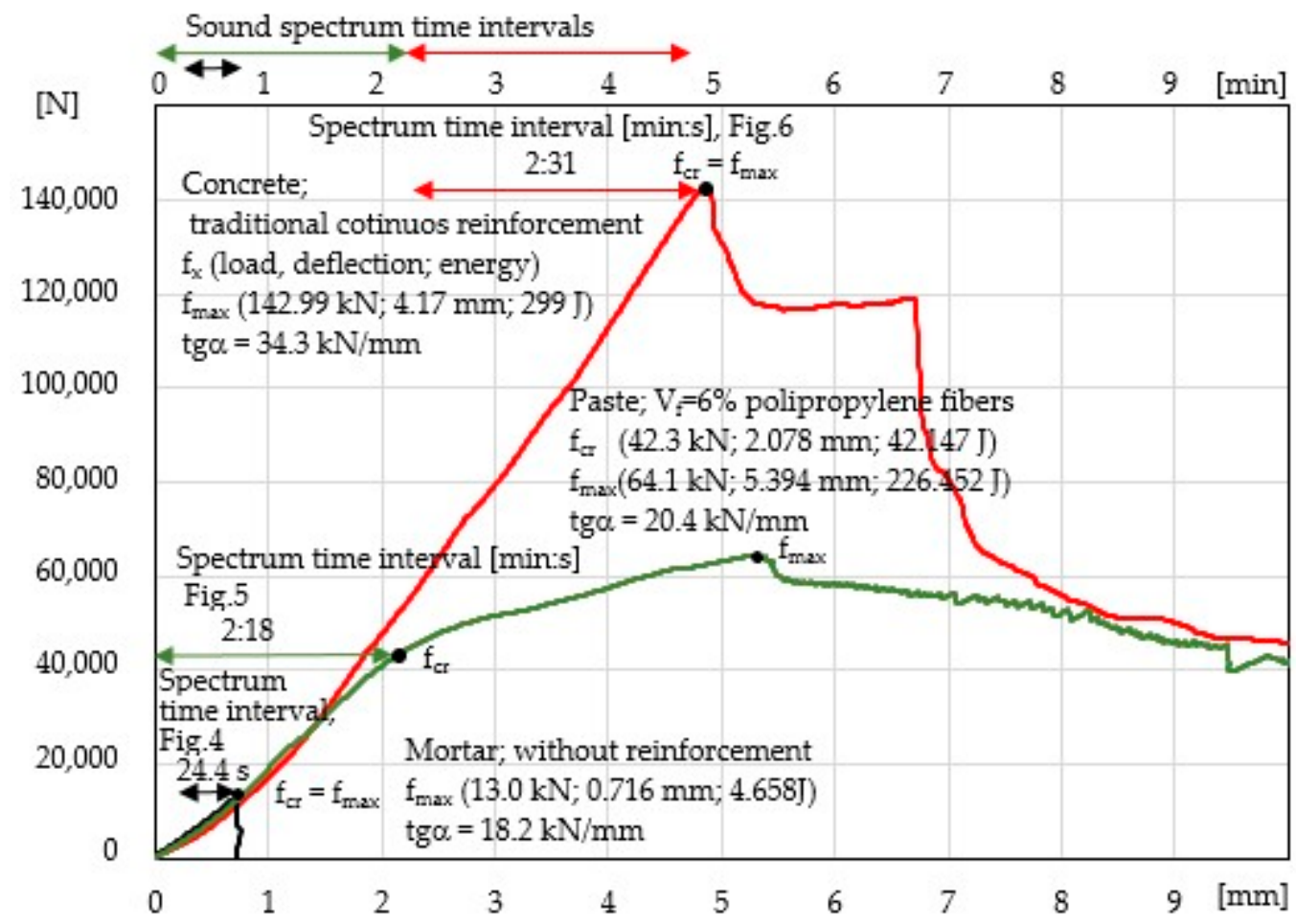

Figure 3. Load-deflection curves of the specimens during the bending test with the analysed sound spectrum time intervals.

A cement paste specimen with the maximum possible volume of polypropylene fibres $\mathrm{V}_{\mathrm{f}}=6 \%$ shows a significant improvement in the ability to carry stress in the Hooke's law range, i.e., $\mathrm{f}_{\mathrm{cr}}(42.3 \mathrm{kN} ; 2.078 \mathrm{~mm} ; 42.147 \mathrm{~J})$, and $\operatorname{tg} \alpha=20.4 \mathrm{kN} / \mathrm{mm}$. It is a typical ESD composite with a significant strengthening control range $A_{s}$. The multicracking effects occur in that area. At point $f_{\max }$, the following results were obtained: $f_{\max }(64.1 \mathrm{kN} ; 5.394 \mathrm{~mm}$; $226.452 \mathrm{~J}$ ), and $\operatorname{tg} \alpha=20.4 \mathrm{kN} / \mathrm{mm}$. After that point, further destruction processes based on the sound spectrum in the deflection control area $A_{D}$ and the destruction propagation area $A_{P}$ were not been analysed in this paper.

A concrete specimen with traditional continuous reinforcement demonstrates a strong ability to carry stress in the elastic range $A_{E}$. After critical stress at the characteristic point $\mathrm{f}_{\mathrm{cr}}=\mathrm{f}_{\max }$, a macrocrack occurs with $\mathrm{f}_{\max }(142.99 \mathrm{kN} ; 4.17 \mathrm{~mm} ; 299 \mathrm{~J})$ and $\operatorname{tg} \alpha=34.3 \mathrm{KN} / \mathrm{mm}$. A significant drop in force is visible after exceeding $\mathrm{f}_{\max }$ by ca. $16 \%$, but a further destruction process is limited by the continuous reinforcement's ability to carry stress to the deflection of $6.7 \mathrm{~mm}$. Another deformation results in the catastrophic destruction process.

The results of the acoustic emission measurement for all specimens are presented in the same manner (in the same amplitude and frequency range), see Figures 4-6. The measurement range of the head limits the AE measurement to the range of $0.2-20 \mathrm{kHz}$. The lower diagrams present the 3D sound spectrum. Below the 3D spectrum, the 2D spectrum amplitude in the range from -10 to $-130 \mathrm{~dB}$ was placed. Due to the lack of possibility of 
presenting all the results from the entire destruction process, only the most characteristic ranges of the sound spectrum are presented, mainly those connected with micro-events preceding $f_{c r}$ and $f_{\max }$. The load-deflection test and the AE measurement (mortar and concrete) did not begin at the same time. The time ranges for mortar and concrete precede the occurrence of $\mathrm{f}_{\mathrm{cr}}$.

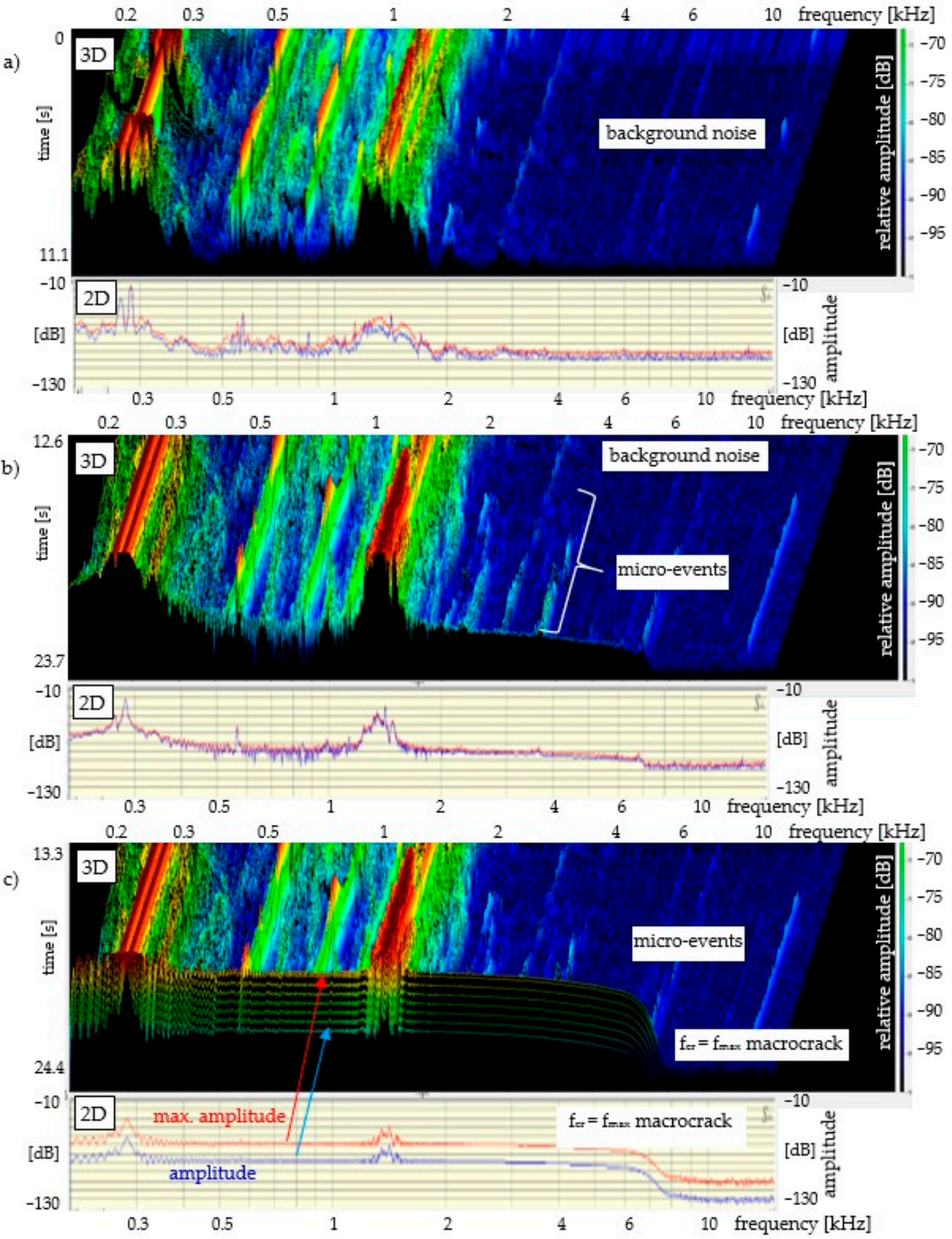

Figure 4. Mortar without reinforcement: bending test-AE; sound spectrum 3D and 2D: (a) background noise; (b) microevents; (c) micro-events and macrocrack $\mathrm{f}_{\mathrm{cr}}=\mathrm{f}_{\max }$. 

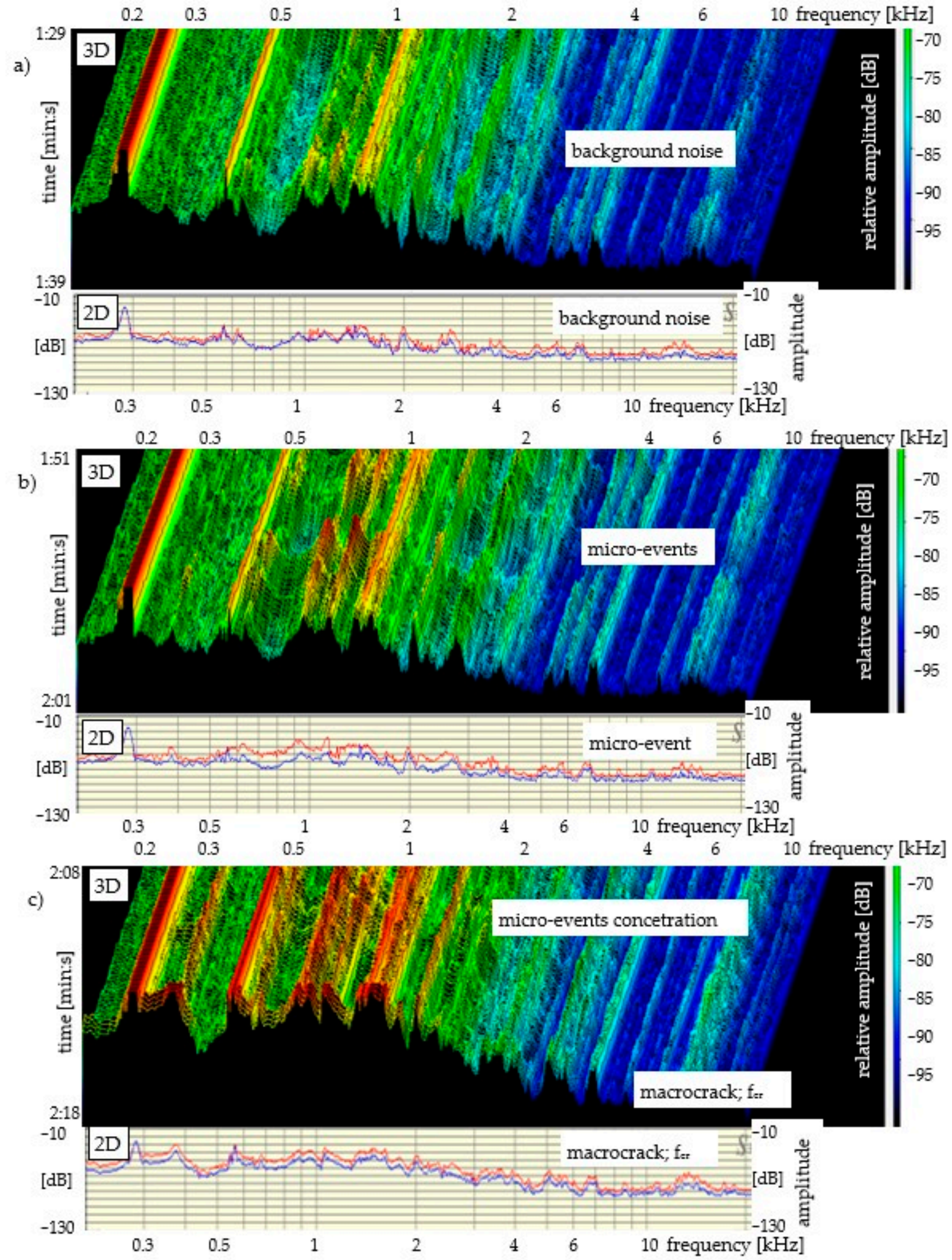

Figure 5. Cement paste with $\mathrm{V}_{\mathrm{f}}=6 \%$ in the bending test and the $\mathrm{AE}$, with $3 \mathrm{D}$ and $2 \mathrm{D}$ sound spectra: (a) background noise; (b) micro-events; (c) fcr and micro-events concentration. 

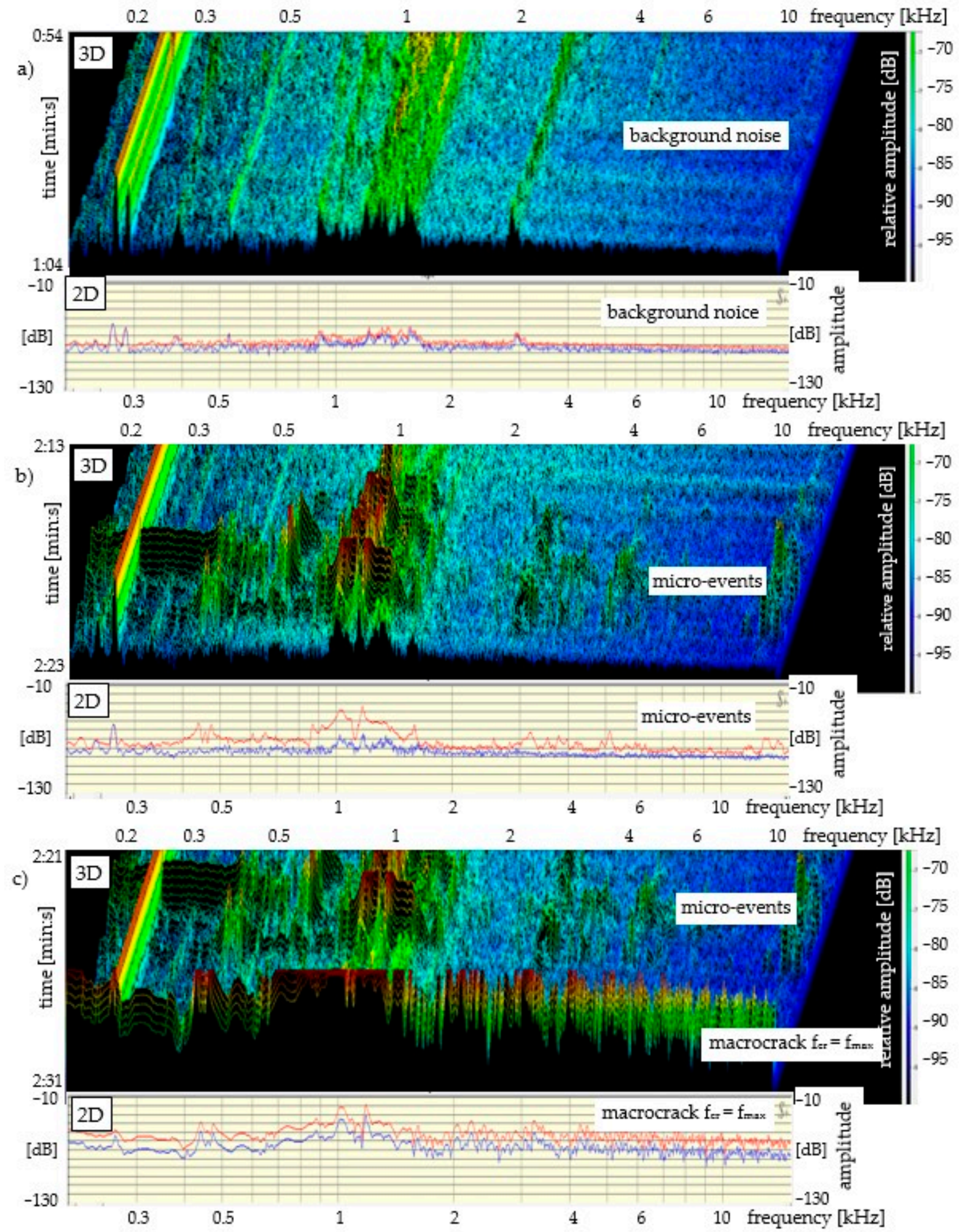

Figure 6. Concrete with traditional continuous reinforcement during the bending test and the AE, with 3D and 2D sound spectra: (a) background noise; (b) micro-events; (c) micro-events and macrocrack $f_{c r}=f_{\text {max }}$.

Figure 4 presents a 3D and 2D sound spectrum of a mortar specimen without reinforcement (AE measurement during the four-point bending test). The background noise spectrum is presented at the top of Figure $4 \mathrm{a}$. Figure $4 \mathrm{~b}$ shows micro-events (increase in relative amplitudes before $\mathrm{f}_{\mathrm{cr}}$ ). The spectrum corresponding to the critical crack (macrocrack; $f_{c r}=f_{\max }$ ) is shown in Figure $4 c$. The brittle composite has been destroyed by a 
macrocrack after reaching the critical point $f_{c r}=f_{\max }$. Based on the amplitudes and the frequency range of $0.2-20 \mathrm{kHz}$ of the 2D spectrum, a detailed description can be given of each spectrum corresponding to the elastic range, strengthening control and deflection control. The load-deflection test and the AE measurement (mortar) did not begin at the same time. The duration of the load-deflection test was circa $40 \mathrm{~s}$ (Figure 3). The sound spectrum time range was shorter and equalled $24.4 \mathrm{~s}$; this time range preceded the occurrence of $\mathrm{f}_{\mathrm{cr} \text {. The }}$ sound spectrum time range was marked on the left-side part of Figure 4c, 3D. Figure 4a presents the 3D sound spectrum in the range from 0 to $11.1 \mathrm{~s}$, which corresponds to the background noise. As is shown in Figure $4 b, c$, the micro-events begin to concentrate circa $9 \mathrm{~s}$ before $\mathrm{f}_{\mathrm{cr}}=\mathrm{f}_{\max }$ and then they increase up to $\mathrm{f}_{\mathrm{cr}}=\mathrm{f}_{\max }$; this 9-s period of time is within the range between $2 / 3$ of $f_{c r}$ and $f_{c r}=f_{\max }$ (load), see Figure 3 .

Figure 5 presents the 2D and 3D sound spectra for a beam made of cement paste with dispersed reinforcement $V_{f}=6 \%$. As is shown by the load-deflection correlation in Figure 3 , the specimen is a typical ESD composite. The load-deflection test and the AE measurement (cement paste) began at the same time and lasted $138 \mathrm{~s}$ (Figure 3). Figure 5a presents the 3D sound spectrum of the background noise whose time range equals $10 \mathrm{~s}$. Micro-events start to appear circa $27 \mathrm{~s}$ before $\mathrm{f}_{\mathrm{cr}}$, then they concentrate circa $8 \mathrm{~s}$ before $\mathrm{f}_{\mathrm{cr}}$ and increase up to $f_{c r}=f_{\max }$, see Figure $5 b$,c; this 27-s period of time (from the moment the micro-events start to appear to $\left.f_{c r}\right)$ is within the range of $2 / 3$ of $f_{c r}$ and $f_{c r}=f_{\max }$ (load), see Figure 3.

Figure 6 presents the AE results for a concrete specimen reinforced with traditional continuous reinforcement; this specimen is characterised by the largest elastic range. The background noise spectrum is presented in Figure 6a. Figure $6 \mathrm{~b}$ shows the spectrum of micro-events preceding $f_{c r}=f_{\max }$, and Figure $6 \mathrm{c}$ presents the spectrum of the macrocrack $f_{c r}=f_{\max }$ and the spectrum of micro-events preceding $f_{c r}$. The load-deflection test and the $\mathrm{AE}$ measurement (concrete) did not begin at the same time. The duration of the loaddeflection test was circa $290 \mathrm{~s}$ (Figure 3). The sound spectrum time range was shorter and equalled $91 \mathrm{~s}$; this time range preceded the occurrence of $\mathrm{f}_{\mathrm{cr}}$. The time was marked on the left-side part of Figure 6c, 3D. Figure 6a presents the 3D sound spectrum of the background noise whose time range equals $10 \mathrm{~s}$. As is shown by Figure $6 \mathrm{c}$, the micro-events begin to concentrate circa 9-10 $s$ before the $\mathrm{f}_{\mathrm{cr}}=\mathrm{f}_{\max }$ point; this 9-10-s period of time is within the range of $2 / 3$ of $f_{\text {cr }}$ and $f_{\text {cr }}=f_{\text {max }}$ (load), see Figure 3 .

\section{Discussion}

It has been confirmed that the load-deflection curve enables the identification of the proportionality, strengthening, deflection control and crack propagation areas, see Figure 3. The rapid decreases in the ability to carry stress that were recorded on the load-deflection curve indicate the appearance of macrocrack and fibre breaking, see Figures 3-6.

The recognition of the range of micro-events (using sound spectrum) preceding the critical crack at point $f_{c r}=f_{\max }$ is the main focus of research in this paper. In cement composites (with or without reinforcement), which are characterised by a significant decrease in stress after exceeding $\mathrm{f}_{\mathrm{cr}}$, the recording of micro-events is relatively easy to recognise. The recording of micro-events begins at the point corresponding to circa $2 / 3$ of $f_{c r}=f_{\max }$ of the stress in the elastic range, see Figure 4 . The concentration of micro-events and the corresponding amplitude range increase as point $\mathrm{f}_{\mathrm{cr}}=\mathrm{f}_{\max }$ is being approached. The above observations are illustrated in the form of a diagram in Figure 7. The analysis regarding the range of micro-events occurrence was carried out based on Figures 4-6 and the presented data.

In the case of ESD composites without the decrease in stress after exceeding $f_{c r}$ (e.g., owing to multicracking in the cement paste with $V_{f}=6 \%$, see Figures 3 and 5), microevents in the elastic range (the same as in composites $\mathrm{f}_{\mathrm{cr}}=\mathrm{f}_{\mathrm{max}}$ ) can be recorded. However, it should be noted that the recognition of the sound spectrum corresponding to $f_{c r}$ as well as the spectra of micro-events preceding $f_{c r}$ is more difficult. This results from the fact that microcracks at point $f_{c r}$ generate smaller acoustic effects than at point $f_{c r}=f_{\max }$ 
(composites characterised by a decrease in stress at the critical point). At the same time, the concentration of events and increase in amplitudes before $f_{\max }$ in the tested composite were also recorded. The diversified range of the strengthening control area resulting from the diversified destruction range makes it difficult to estimate the range of occurrence of micro-events before $f_{\max }$.

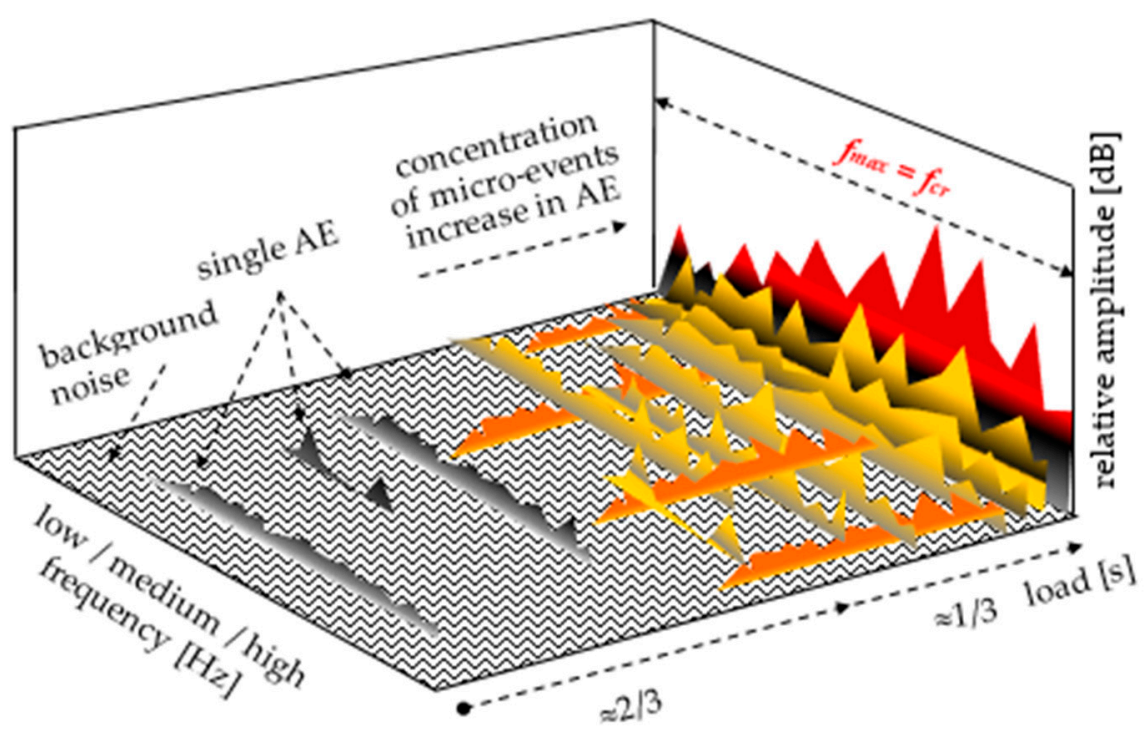

Figure 7. The range of micro-events in cement composites $\left(f_{c r}=f_{\max }\right)$ identified by means of a space sound spectrum.

An analysis of the time range of micro-event occurrence recorded in other papers with respect to $f_{c r}$ and $f_{\max }$ is similar $[46,47]$. Micro-events were observed in all other tested specimens, small- and large-size ones, with and without cuts, and with various types of reinforcement. It seems that the conclusions drawn in this respect could be extended to the majority of cement composites.

It should be noted that the speed of crosshead displacement in the process of recognising micro-events in future tests should be significantly reduced. In addition, heads used to record AE should be located in places of applied forces and supports. It has also been noted that the frequency range should be expanded by adding low and high frequency and infrasound spectra, which will probably provide additional information, facilitating the identification of the destruction process.

Micro-events relate to changes at the microstructure level; this destruction process is not visible and requires identification in the future by means of scanning or a microscope. The occurrence of micro-events may be attributed to microcracks connected with the redistribution of stress. They may concentrate in areas subjected to tension or in places where the load is applied. The concentration of stress also occurs at the point of contact between a specimen and the supports on which the beams were placed. The confirmation or refutation of the above suggestions requires additional tests that are planned to be carried out in the near future.

The correct identification of micro-events with the corresponding range of stresses in the elastic range may reduce the level of stresses in the calculations (especially with the cyclical application of dynamic load) in order to increase the durability of structural elements, which so far has not been the focus of interest.

There are lots of variables (location of the sensor, type and geometry of the sensor and sample and background noise) that make it difficult to compare this study with other similar experiments. The identification of micro-events should be expanded for a larger number of specimens with varied geometry, which will serve as the basis for the statistical processing of the results. An attempt to use the presented method conducted under a 
load-deflection test to monitor building structures based on cement composites is not practical but an effort to record and identify the micro-events (before the occurrence of $f_{c r}$ ) correlated with the stress level seems to be worth making.

\section{Conclusions}

It has been confirmed that there is a possibility of predicting the occurrence of microevents in cement composites, which occur at the end of the Hooke's law range $f_{c r}=f_{\max }$.

It has been found that, in cement composites, for which $\mathrm{f}_{\mathrm{cr}}=\mathrm{f}_{\max }$, micro-events occur after exceeding $2 / 3$ of the stress elastic range, and the concentration and amplitude of the sound spectrum increase before the critical crack occurs.

Recording micro-events in quasi-brittle cement composites (in which there is no rapid decrease in stress after exceeding critical points $f_{c r}$ and $f_{\max }$ ) is also possible, but the range of occurrence of micro-events and the correlated spectrum amplitudes are smaller, which make it more difficult to locate and recognize them.

The micro-events process is not visible and requires identification in the future by means of scanning or a microscope. This phenomenon may be connected with micro-cracks or regrouping of stresses in the structure of the material or with effects occurring at the place of the applied load, which should be confirmed in future tests.

The correct identification of micro-events with the corresponding range of stresses in the Hooke's law area may reduce the level of stresses adopted for the calculation (especially with the cyclical dynamic load), in order to increase the durability of the structural elements.

Author Contributions: Conceptualization, methodology-writing, D.L.; review and analyzed the test results J.J.; supervision and editing Z.K.; review and editing P.F. All authors have read and agreed to the published version of the manuscript.

Funding: The authors from the Brno University of Technology thanks the financial support of the Czech Science Foundation under project No. 19-09491S (MUFRAS). This research received no external funding.

Institutional Review Board Statement: Not applicable.

Informed Consent Statement: Not applicable.

Data Availability Statement: No new data were created or analyzed in this study. Data sharing is not applicable to this article.

Acknowledgments: Not applicable.

Conflicts of Interest: The author declares no conflict of interest.

\section{References}

1. Ohtsu, M. Determination of crack orientation by acoustic emission. Mater. Eval. 1987, 45, 1070-1075.

2. Ohtsu, M. The history and development of acoustic emission in concrete engineering. Mag. Concr. Res. 1996, 48, 321-330. [CrossRef]

3. Ouyang, C.S.; Landis, E.; Shh, S.P. Damage assessment in concrete using quantitative acoustic emission. J. Eng. Mech. 1991, 117, 2681-2698. [CrossRef]

4. Ranachowski, Z. Method of measurement and analysis of acoustic emission signal. IPPT Pan Pap. 1997, 1, 113. (In Polish)

5. Kucharska, L.; Brandt, A.M. Pitch-based carbon fibre reinforced cement composites. In Materials Engineering Conference ASCE. Materials for the New Millenium; Chong, K.P., Ed.; American Society of Civil: Washington, DC, USA; American Society of Civil Engineers (book): New York, NY, USA, 1996; Volume 1, pp. 1271-1280.

6. Brandt, A.M. Fibre reinforced cement-based (FRC) composites after over 40 years of development in building and civil engineering. Compos. Struct. 2008, 86, 3-9. [CrossRef]

7. Dzayea, E.D.; Schutterb, G.D.; Aggelisa, D.G. Monitoring early-age acoustic emission of cement paste and fly ash paste. Cem. Concr. Res. 2020, 129, 105964. [CrossRef]

8. Assi, L.; Soltangharaei, V.; Anay, R.; Ziehl, P.; Matta, F. Unsupervised and supervised pattern recognition of acoustic emission signals during early hydration of Portland cement paste. Cem. Concr. Res. 2018, 103, 216-225. [CrossRef]

9. Elaqra, H.; Godin, N.; Peix, G.; R'Mili, M.; Fantozzi, G. Damage evolution analysis in mortar, during compressive loading using acoustic emission and X-ray tomography: Effects of the sand/cement ratio. Cem. Concr. Res. 2007, 37, 703-713. [CrossRef] 
10. Šimonová, H.; Topolář, L.; Schmid, P.; Keršner, Z.; Rovnaník, P. Effect of carbon nanotubes in metakaolin-based geopolymer mortars on fracture toughness parameters and acoustic emission signals. In Proceedings of the BMC 11 International Symposium on Brittle Matrix Composites, Warsaw, Poland., 28-30 September 2015; pp. 261-288.

11. Chen, B.; Liu, J. Experimental study on AE characteristics of free-point-bending concrete beams. Cem. Concr. Res. 2004, 34, 391-397. [CrossRef]

12. Ranachowski, Z.; Schabowicz, K. The contribution of fibre reinforcement system to the overall toughness of cellulose fibre concrete panels. Constr. Build. Mater. 2017, 156, 1028-1034. [CrossRef]

13. Schabowicz, K.; Gorzelańczyk, T.; Szymków, M. Identification of the degree of degradation of fibre-cement boards exposed to fire by means of the acoustic emission method and artificial neural networks. Materials 2019, 12, 656. [CrossRef] [PubMed]

14. Ranachowski, Z.; Jóźwiak-Niedźwiedzka, D.; Brandt, A.M.; Dębowski, T. Application of acoustic emission method to determine critical stress in fibre reinforced mortar beams. Arch. Acoust. 2012, 37, 261-268. [CrossRef]

15. Brandt, A.M.; Ranchowski, Z.; Zieliński, M.; Dabrowski, M.; Sobczak, M. Report from Tests of Cracking Resistance of Bent Cement Composite Samples; Polish Academy of Science Institute of Fundamental Technology Problems: Warsaw, Poland, 2010.

16. Aggelis, D.G.; Mpalaskas, A.C.; Matikas, T.E. Investigation of different modes in cement-based materials by acoustic emission Cem. Concr. Res. 2013, 48, 1-8. [CrossRef]

17. Kim, B.; Weiss, W.J. Using acoustic emission to quantify damage in restrained fibre-reinforced cement mortars. Cem. Concr. Res. 2003, 33, 207-214. [CrossRef]

18. Landis, E.; Ballion, L. Experiments to relate acoustic energy to fracture energy of concrete. J. Eng. Mech. 2002, 128, 698-702. [CrossRef]

19. Paul, S.C.; Pirskawetz, S.; Zijl, G.P.A.G.; Schmidt, W. Acoustic emission for characterising the crack propagation in strainhardening cement-based composites (SHCC). Cem. Concr. Res. 2015, 69, 19-24. [CrossRef]

20. Reinhardt, H.W.; Weiler, B.; Grosse, C. Nondestructive testing of steel fibre reinforced concrete. Brittle Matrix Compos. 2000, 6, 17-32.

21. Shahidan, S.; Rhys Pulin, R.; Bunnori, N.M.; Holford, K.M. Damage classification in reinforced concrete beam by acoustic emission signal analysis. Constr. Build. Mater. 2013, 45, 78-86. [CrossRef]

22. Shiotani, T.; Li, Z.; Yuyama, S.; Ohtsu, M. Application of the AE improved b-value to quantitative evaluation of fracture process in Concrete Materials. J. Acoust. Emiss. 2004, 19, 118-133.

23. Soulioti, D.; Barkoula, N.M.; Paipetis, A.; Matikas, T.E.; Shiotani, T.; Aggelis, D.G. Acoustic emission behavior of steel fibre reinforced concrete under bending. Constr. Build. Mater. 2009, 23, 3532-3536. [CrossRef]

24. Watanab, K.; Niwa, J.; Iwanami, M.; Yokota, H. Localized failure of concrete in compression identified by AE method. Constr. Build. Mater. 2004, 18, 189-196. [CrossRef]

25. Yuyama, S.; Ohtsu, M. Acoustic Emission evaluation in concrete. In Acoustic Emission-Beyond the Millennium; Kishi, T., Ohtsu, M., Yuyama, S., Eds.; Elsevier: Amsterdam, The Netherlands, 2000; pp. 187-213.

26. Ohno, K.; Ohtsu, M. Crack classification in concrete based on acoustic emission. Constr. Build. Mater. 2010, 24, 2339-2346. [CrossRef]

27. Granger, S.; Pijaudier, G.; Loukili, A.; Marlot, D.; Lenain, J.C. Monitoring of cracking and healing in an ultra high performance cementitious material using the time reversal technique. Cem. Concr. Res. 2009, 39, 296-302. [CrossRef]

28. Ohtsu, M. Elastic wave methods for NDE in concrete based on generalized theory of acoustic emission. Constr. Build. Mater. 2016, 122, 845-855. [CrossRef]

29. Ono, K.; Gołaski, L.; Gębski, P. Diagnostic of reinforced concrete bridges by acoustic emission. J. Acoust. Emiss. 2002 , $20,83-98$.

30. Parmar, D. Non-Destructive Bridge Testing and Monitoring with Acoustic Emission (AE) Sensor Technology; Final Report; Hampton University: Hampton, VA, USA, 2011.

31. Swit, G. Acoustic Emission Method for Locating and Identifying Active Destructive Processes in Operating Facilities. Appl. Sci. 2018, 8, 1295. [CrossRef]

32. Anay, R.; Soltangharaei, V.; Assi, L.; DeVol, T.; Ziehl, P. Identification of damage mechanisms in cement paste based on acoustic emission. Constr. Build. Mater. 2018, 164, 286-296. [CrossRef]

33. Ai, Q.; Liu, C.C.; Chen, X.R.; He, P.; Wang, Y. Acoustic emission of fatigue crack in pressure pipe under cyclic pressure. Nucl. Eng. Des. 2010, 240, 3616-3620. [CrossRef]

34. Seitl, S.; Miarka, P.; Šimonová, H.; Frantík, P.; Keršner, Z.; Domski, J.; Katzer, J. Change of fatigue and mechanical fracture properties of a cement composite due to partial replacement of aggregate by red ceramic waste. Period. Polytech.-Civ. Eng. 2019, 1, 152-159. [CrossRef]

35. Šimonová, H.; Kumpová, I.; Rozsypalová, I.; Bayer, P.; Frantík, P.; Rovnaníková, P.; Keršner, Z. Fracture parameters of alkaliactivated aluminosilicate composites with ceramic precursor. In 26th Concrete Days. Solid State Phenomena; Trans Tech Publications Ltd.: Bäch, Switzerland, 2020; pp. 73-79. ISBN 978-3-0357-1668-9. ISSN 1662-9779.

36. Juraszek, J. Influence of the spatial structure of carbon fibres on the strength properties of a carbon composite. Fibres Text. East. Eur. 2019, 27, 111-115. [CrossRef]

37. Juraszek, J. Fiber bragg sensors on strain analysis of power transmission lines. Materials 2020, 13, 1559. [CrossRef]

38. Juraszek, J. Strain and force measurement in wire guide. Arch. Min. Sci. 2018, 63, 321-334. 
39. Kowalik, T.; Logoń, D.; Maj, M.; Rybak, J.; Ubysz, A.; Wojtowicz, A. Chemical hazards in construction industry. In Proceedings of the XXII International Scientific Conference on Construction the Formation of Living Environment (FORM-2019), Tashkent, Uzbekistan, 18-21 April 2019; Volkov, A., Pustovgar, A., Sultanov, T., Adamtsevich, A., Eds.; E3S Web of Conf. EDP Sciences, 2019; Volume 97, p. 03032, ISSN 2267-1242.

40. Tsangouri, E.; Michels, L.; El Kadi, M.; Tysmans, T.; Aggelis, D.G. A fundamental investigation of textile reinforced cementitious composites tensile response by Acoustic Emission. Cem. Concr. Res. 2019, 123, 105776. [CrossRef]

41. Van Steen, C.; Verstrynge, E.; Wevers, M.; Vandewalle, L. Assessing the bond behaviour of corroded smooth and ribbed rebars with acoustic emission monitoring. Cem. Concr. Res. 2019, 120, 176-186. [CrossRef]

42. Kumar Das, A.; Suthar, D.; Leung, C.K.Y. Machine learning based crack mode classification from unlabelled acoustic emission waveform features. Cem. Concr. Res. 2019, 121, 42-57.

43. Logoń, D. FSD cement composites as a substitute for continuous reinforcement. In Proceedings of the Eleventh International Symposium on Brittle Matrix Composites BMC-11, Warsaw, Poland, 28-30 September 2015; Brandt, A.M., Ed.; Institute of Fundamental Technological Research: Warsaw, Poland, 2015; pp. 251-260.

44. Logon, D. Identification of the destruction process in quasi brittle concrete with dispersed fibres based on acoustic emission and sound spectrum. Materials 2019, 12, 2266. [CrossRef] [PubMed]

45. Logon, D. Monitoring of microcracking effect and crack propagation in cement composites (HPFRC) using the acoustic emission (AE). In Proceedings of the 7th Youth Symposium on Experimental Solid Mechanics, YSESM '08, Wojcieszyce, Poland, 14-17 May 2008.

46. Logon, D. The application of acoustic emission to diagnose the destruction process in FSD cement composites. In Proceedings of the International Symposium on Brittle Matrix Composites BMC-11, Warsaw, Poland, 28-30 September 2015; Brandt, A.M., Ed.; Institute of Fundamental Technological Research: Warsaw, Poland, 2015; pp. 299-308.

47. Logon, D.; Schabowicz, K. The recognition of the micro-events in cement composites and the identification of the destruction process using acoustic emission and sound spectrum. Materials 2020, 13, 2988. [CrossRef] [PubMed]

48. Logon, D.; Schabowicz, K. The increase in the elastic range and strengthening control of quasi brittle cement composites by low-module dispersed reinforcement-The assessment of reinforcement effects. Materials 2021, 14, 341. [CrossRef]

49. ASTM 1018. Standard Test Method for Flexural Toughness and First Crack Strength of Fibre-Reinforced Concrete; ASTM: Philadelphia, PA, USA, 1992; Volume 04.02. 